\title{
Community Participation as a Strategy to Address Water Shortage: A Tale of Bigwa and Lukuyu Wards in Morogoro
}

\author{
Idda Lyatonga Swai (Corresponding author) \\ School of Public Administration and Management \\ Mzumbe University, PO Box 2, Mzumbe, Morogoro, Tanzania \\ E-mail: imaswa@yahoo.com
}

Received: September 05, 2016 Accepted: October 01, 2016 Published: October 08, 2016

doi:10.5296/jpag.v6i3.10021 URL: http://dx.doi.org/10.5296/jpag.v6i3.10021

\begin{abstract}
The efforts to involve the community in determining their own destination in terms of needs and resources can only be achieved when citizens play an active role and at some degree demonstrate significant power and influence on decisions. Community power and influence are key elements embedded in the governance circle. Community participation in the governance, ceteris Paribas, enhances citizens' skills and capacity to support their own projects. Therefore, the notion of community participation cannot be overemphasized. The thorough examination of it at its initial stage is imperative. In that regard, this article examines how local community members of Bigwa and Lukuyu wards participated in MABILU water project. Data were collected from ordinary members of the respective wards, Ward Executive Officers (WEOs), neighbourhood chairpersons and water project representatives. Interview and Content analysis were used to collect and analyse the data respectively.

The results indicate that the successfulness of MABILU water project was attributed by the fact that the citizens were involved from the initial stage of decision making to implementation stage. While $63 \%$ of the participants confirmed to have participated in initiating and decision making about the project, $80 \%$ of total respondents confirmed to have participated in the implementation stage. The findings shows that community members participated in digging and burying trench, contributing money to facilitate the implementation, carrying building materials and cleaning the project area. Some community members participated by encouraging other members to support the project, managing and supervising the projects and supervising the construction of water kiosk.
\end{abstract}

Keywords: Participation, Community participation, water shortage 


\section{Introduction}

Community participation in governance is an important pillar. In any democratic country worldwide, including Tanzania, it is regarded as an integral part of social, economic and political activities. The concept of community participation in development process has been an important concept for more than two decades (Njunwa, 2010). Community Participation concerns with the engagement of individuals and communities in the decisions that affect their lives. Community participation is only archived when the citizens play an active part and have significant degree of power and influence on the decisions. Community participation in Tanzania is required by the URT Constitution Article 21 which affirms that every citizen of the United Republic of Tanzania has the right to participate in the governance of the country either directly or through their representative (URT, 1998). The constitution shows as strong recognition of the importance of participation in archiving the much sought social and economic development in the country. This was supported by the first president of United Republic of Tanzania who made a powerful statement on the need for participation of the people in community development. He stated that:

'Development is the participation of people in a mutual learning experience involving themselves, their local resources, external change agents and outside resources. People cannot be developed; they can only develop themselves by participation and cooperative activities which affect their wellbeing. People are not being developed when they herded like animals into new ventures' (Nyerere, 1968).

The involvement of the local community is important in bringing about local development. When people at the community participate in the decisions that affect their lives, they feel attached to the decisions and actively participate in the implementation process which increases sense of ownership of the projects. According to Pateman (1970), participation was taken as collective sustained activity for the purpose of achieving common objectives, especially a more equitable distribution of the benefits of development. Individuals and groups are able to pursue conflicting interests and compete for scarce resources when they participate in the implementation process. This is to empower the community to solve their own problem and stimulates self-reliance among the community (JOICFP, 2000). There are often genuine reasons as to why people wish to participate in development projects when they are given opportunity to do so (Theron, 2005). Depending on the motivation and the existed opportunity, the local people can participate in activities such as needs assessment, planning, mobilizing, implementation and monitoring and evaluation of community projects. It is in this epoch that the government has gained momentum to involve citizens in their own development as a mechanism to bring change in social political and economic issues. The politicians and the government are now encouraging the local government authorities to involve people in development process because it is believed that for the community to achieve sustainable development there must be community's participation in development projects (Njunwa, 2010). This article examines how community participate in initiation and implementation of water project in Bigwa and Lukuyu wards in MMC. 


\section{Conceptualizing Community Participation}

Community participation has become one of the fashionable concepts within the development discourse of the $21^{\text {st }}$ century. It is an important pillar in the governance of any democratic country worldwide. It is however, noted that the direct involvement of ordinary people in designing, implementation and evaluation of planning, governance and overall development projects at the grassroots level has become an integral part of democratic countries in recent years (Sibiya, 2010). The concept of "community participation" is regarded as a tool to assist in local development in rural communities. It is an umbrella term for supposedly new genre of development intervention (Tosun, 2000). It is the heart and core of community development that empowers the community to solve their own problem (JOICFP, 2000, Fariborz and Ma rof, 2008). It is a necessary condition for the development and maintenance of effective community development in different perspectives and it is largely become a requirement and pre-requisite for funding of development initiatives by many donors. Community development has increasingly placed an emphasis on sustainability. Thus, community participation has become an important opportunity for community development and it is regarded as an indispensable part of sustainable socio-economic and political development. Community participation also presents a challenge to community development, as it often requires an investment of time, energy and tangible resources to build the community capacity to understand and respond to the prevailing problems. Community participation is a fundamental principle of democracy. It can be defined as the involvement of people in a community projects to solve their own problems. Community participation can be seen as a process whereby residents of the community are given a voice and choice to participate in issues affecting their lives (Theron, 2005).

Participation in some form or the other has been included as an important element in development strategies of countries in sub-Saharan Africa. Indeed, participation has become an essential ingredient and a prerequisite of good governance. Development as a process of increasing people's capacity to determine their future means that people need to be included in the process - the need to participate. Participation or empowerment is part of the process and definition of development. There is, therefore, a growing consensus that people everywhere have a basic human right to take part in decisions that affect their lives. Therefore, participation is defined as a form of action performed by private citizens or group of people which has the intention of influencing activities of the government or the decisions (Verba, et al 1995:38, Teorell, 2006). According to Pateman (1970), participation was taken as collective sustained activity for the purpose of achieving common objectives, especially a more equitable distribution of the benefits of development.

Successful community participation in issues affecting lives of people should be viewed at different levels: At the structural level there is a need for professional support and commitment to community participation, expert skills, and human resources dedication to support participation that will be responsive to local community involvement (Masanyiwa and Kinyashi, 2008). At the operational level a number of inputs are important to optimize the success of involving people to community issues, namely political will and political support, which has principles aligned with that of community participation, coordination, 
collaboration, communication, available information, and administrative support (Tosun, 2000). At the cultural level there is a need for enthusiasm and increase awareness between local people, inter presentation terms, and processes used to understand community participation (Masanyiwa and Kinyashi, 2008).

According to Masanyiwa and Kinyashi, (2008), a review of literature on the ways in which participation is operationalized in different interventions reveals multiple conceptions of participation. The term participation has been used to build local capacity and self-reliance, but also to justify the extension of control of the state. It has been used to devolve power and decision making away from external agencies, but also to justify external decisions. It has been used for data collection and also for interactive analysis. But more often than not, people are dragged into participating in operations of no interest to them, in the very name of participation. An understanding about the concepts will serve to provide some perspectives of the process and the dynamics involved in it.

Community participation is a key word in the analysis of social development, yet it is intended meaning and implications are subject to diverse interpretation (Mwakasangula \& Fatty, 2013). People define their understanding on community participation differently. The differences have been influenced by social, cultural and historical context (Fundi, 2005).

\subsection{Participation as a Means or an End}

Authors and practitioners view participation as a 'means' and as an 'end'. Participation as means implies the use of participation to achieve some pre-determined goals. It is a way of harnessing rural people's physical, economic and social resources to achieve the aims and objectives of development programmes and projects more efficiently, effectively or cheaply (Nelson and Wright, 1995).

Participation as an end is viewed as an active, dynamic and genuine process which unfolds over time and whose purpose is to develop and strengthen the capabilities of rural people to intervene more directly in development initiatives (Cooke and Kothari, 2001). As an end, participation is seen as the empowerment of individuals and communities in terms of acquiring skills, knowledge and experience, leading to greater self-reliance. The proponents of this view often maintain that development for the benefit of the poor cannot occur unless the poor themselves control the process, the praxis of participation. It is argued that by establishing a process of genuine participation, development will occur as a direct result (Cooke and Kothari, 2001). Table 1 below provides a comparison between participation as means and as an end. 
Table 1: Participation as a means or an end

Participation as Means

It implies use of participation to achieve some predetermined goals or objectives.

It is an attempt to utilize the existing resources in order to achieve the objectives of programmes/projects.

The stress is on achieving the objective and not so much on the act of participation itself.

It is more common in government programmes, where the main concern is to mobilise the community and involve them in improving of the delivery system.

Participation is generally short term.

Appears to be a passive form of participation.

\section{Participation as End}

Attempts to empower people to participate more meaningfully.

The attempt is to ensure the increased role of people in development initiatives.

The focus is on improving the ability of the people to participate rather than just in achieving the predetermined objectives of the project.

This view finds relatively less favour with the government agencies. NGOs in principle agree with this viewpoint.

Viewed as a long term process.

Relatively more active and long term.

Source: Kumar (2002:26)

\subsection{Levels of Participation}

Development agencies and authors distinguish different dimensions, spaces, degrees and levels of participation. Pretty (2003) conceptualizes participation levels in terms of 'weak and strong participation'. According to his views, weak participation involves "informing and consulting" while strong participation referring to "partnership and control" He argues that, in practice agencies managing complex projects find it hard to move from the 'weak end' of the continuum and tend to assume that, intended beneficiaries will be consulted during the project design to take into account their felt needs and aspirations.

The problem with levels of participation is that they imply coherence, when most development organizations operate simultaneously in a wide range of participatory modes. One level on the continuum is not necessarily better than any other as different levels are appropriate at different times and contexts to meet the expectations and interests of different stakeholders (Wilcox, 1994). Oakley (1991) cites an analysis of a Danish funded rural water supply project in Tanzania, where he observes that participation had ranged from non-participation and manipulation over information and consultation to some degree of 
partnership and delegation of power. In another study of Malawi Social Action Fund (MASAF) projects, Dulani (2003) concluded that, the level of community participation was limited to being informed what had already been decided by other key players which implied "passive and consultation participation".

This is linked to typology of participation developed by Amstein (1969), Pretty (1995) and Tosun (1999). There are several ways in which people can participate in the decision making. People can participate by being told what is going to happen or has already happened (passive participation), people participate by being consulted (participation by consultation), and information participation where people participate by answering questions but they do not have an opportunity to influence proceedings. Participation can also be in terms of material incentives where people participate by providing resources, for example labour, in return for food, cash or other material incentives. Functional participation is when people participate by forming groups to meet predetermined objectives related to the project. In this kind of participation the involvement does not occur at the early stages of project cycles, but after major decisions have been made. Participation can also be interactive where numerous stakeholders are involved to make use of systematic and structured learning processes. The groups involved take control over local decisions and they have a stake in maintaining structures or practices. Self-mobilization kind of participation is when people participate by taking initiatives and develop contacts with external institutions for resources and technical advice they need, but retain control over resource use. Such self-initiated mobilisation and collective action may or may challenge existing inequitable distributions of wealth and power.

Table 2: Typology of community participation

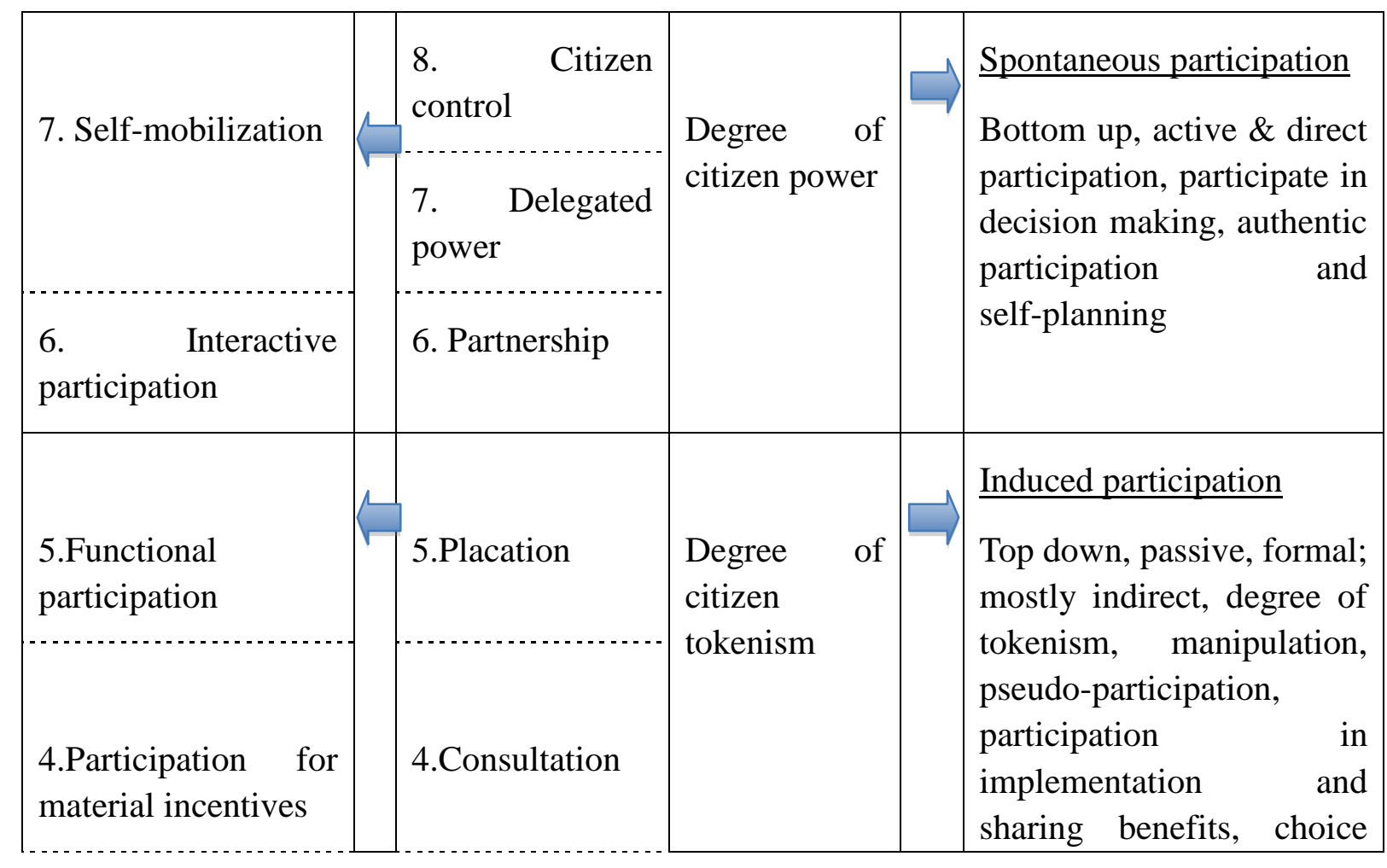




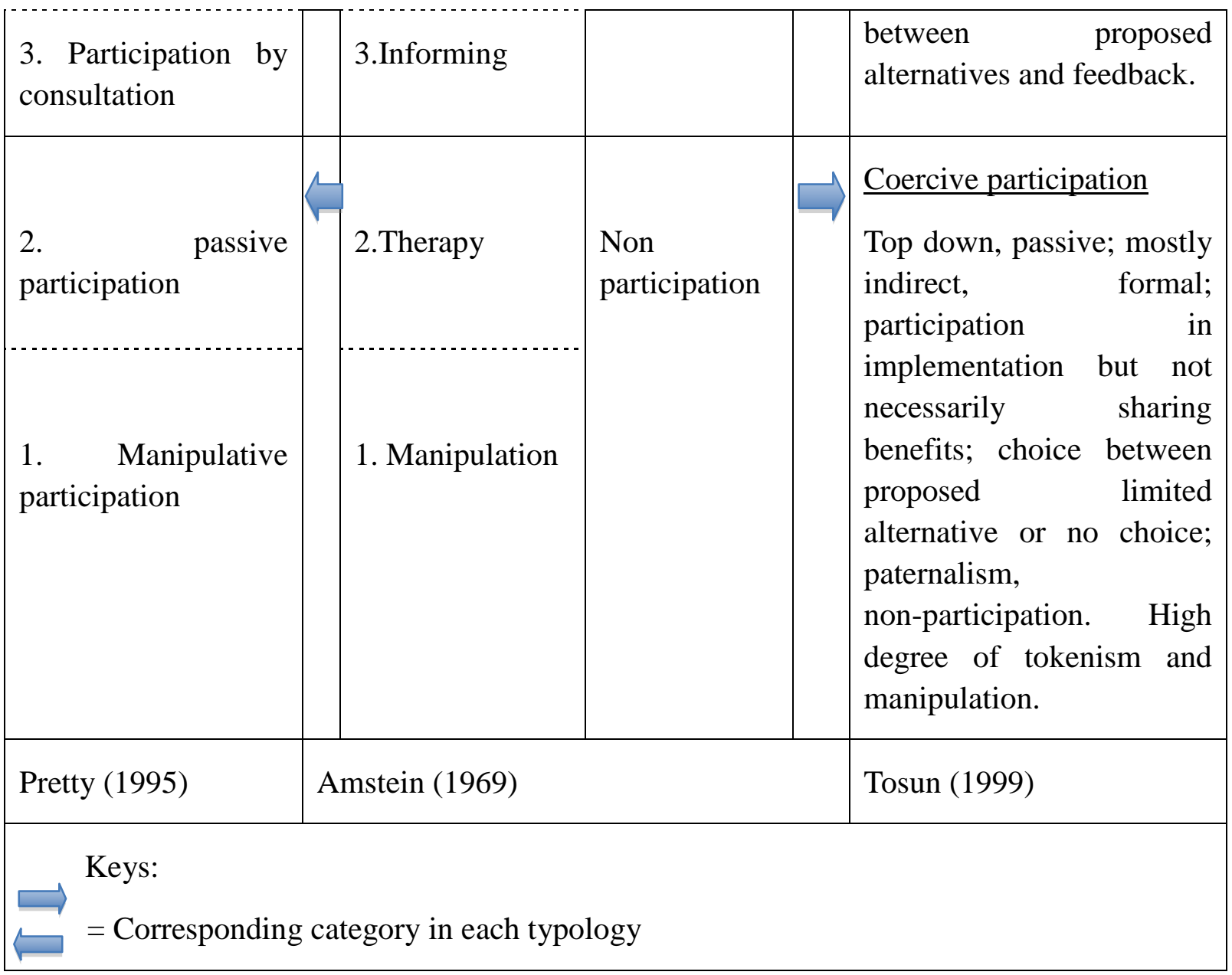

Therefore, it is clear that there is a myriad of aspects of participation. This means that great care must be taken when using and interpreting the terms. It should always be qualified by reference to the type of participation. Indeed, observers seem to agree that the application of participatory approaches further call for an appreciation of the social dynamics and diversities such as gender, age, social status, ethnicity, disability and power amongst others

\subsection{Criteria for Assessing Participation}

For community participation to be effective, it should take into account the accepted and process criteria to assess community participation as shown in table 3 . The acceptance criteria are related to the effective construction and implementation of a procedure and the process criteria are related to the public acceptance of the procedure. The community members should be representatives of the community, the process should be transparent, the members should be involved from the beginning of the process and they should have say on the whole process. Participation is vital for success of any projects and so it should be incorporated at all levels of decision making (Swai, et al, 2013). If the whole process takes into account these criteria then the community members should be aware and committed to the achievements. Participation should therefore touch social, political and economic life of the people involved. 
Table 3: Criteria for Assessing Participation

Acceptance Criteria

Representativeness. The participants should comprise a broadly representative sample of the affected population

Independence. The participation should conduct in an independent and unbiased way. The representatives should be independent of any sponsoring bodies. For example appointment of steering committee should incorporate members from diverse bodies

\section{Early Involvement.}

The target community should be involved as early as possible in the process and allowed to discuss underlying assumptions and agenda setting and not just narrow, predefined problems

Transparency. The process should be transparent so that the public can see what is going on and how decision is being made. This involves releasing information on aspects of the procedure, resourcing the participants to the way in which decisions are reached to records of meetings

\section{Process Criteria}

Access to resources. Public participation should have access to appropriate resources to enable them to successfully fulfil their brief. These include information resource, human resource, material resource and time resource and other media

Task Definition. The nature and scope of the tasks should be clearly defined. It is important to ensure that there is a little confusion and dispute as possible regarding the scope of participation exercise, its expected output and the mechanisms of the procedure

Structured decision making.

The participation exercise should use /provide appropriate mechanisms for structuring and displaying the decision making process. Documenting the process as well as the outcome is like to increase transparency and perceived credibility of the exercise as well as the efficiency of the process.

Cost Effectiveness. The procedure should be cost effective given its primary purpose. It is sensible to compare the cost of chosen method with potential costs of alternative methods in both time and money and to consider the extent to which they fulfil the other criteria

Source: Rowe and Frewer (2000) 
Furthermore, three varieties of participation were identified as written by Nelson and Wright (1995). The three types were horizontal participation which relates to activities to get people involved collectively in efforts to influence policy decisions, the vertical participation which includes any occasions when members of the public develop particular relations with elites or official which is mutually beneficial. The final variety of participation is administrative process which may overlap with the either horizontal or vertical participation. This type take the forms of interest group activity to shape administrative decisions or of a particular exchange between patron and client but usually this type of participation is more inclusive than either of the other two varieties.

Other scholars conceptualize participation levels in terms of weak and strong participation (Pretty, 2003). Weak participation involves informing and consulting while strong participation means partnership and control. This is weak as passive participation where the people are told what to do or required to answer the questions of yes and no. This is a unilateral announcement by political leaders without listening to people's response (Theron, 2005) or even asking their opinion (Kamugisha et al, 2012). In addition, Amstein (1969) classified participation into three levels: non-participation, degree of citizen tokenism and degree of citizen power. The three levels reflects to some extent what Pretty (2003) categorise as weak and strong participation. That is non participation and degree of citizen tokenism is categorised as weak participation while the degree of citizen power is similar to strong participation.

Having seen the theories underpinning community participation and participation as a whole, this article seeks to study community participation in Bigwa and Lukuyu wards with specific reference to MABILU water project. The aim is to examine how the community was involved from the initiation to implementation of the project.

\section{Data and Methods}

The data for this article was collected from Bigwa and Lukuyu wards in Morogoro Municipal Council (MMC) which is located in eastern part of Tanzania. MMC is the Headquarter of Morogoro region and it is situated on the slopes of Uluguru Mountains rising to about 1,600 feet above the sea level. MMC has the total land area of 260 sq. $\mathrm{km}$, constituting 4 percent of the total regional area. The major physical features include the Uluguru Mountains, which lie in the south east and Mindu mountains in the west (MMC 2008). Despite the variation of climatic conditions throughout the year, the weather is very attractive because of its high altitude. MMC experiences average daily temperature of $27 \mathrm{C}$ to $30 \mathrm{C}$ degrees with daily range of about 5 degrees centigrade. The major economic activity in Morogoro municipality is agriculture where majority of the population are the farmers (substance and commercial farming). Other economic activities include industrial activities, small-scale enterprise. The Morogoro Municipal Council as one of Local Government Authority (LGAs) is responsible for the provision of services in area of its jurisdiction. It supervises the implementation of projects among them being MABILU water project in Bigwa and Lukuyu wards. 


\section{Mll Macrothink}

Journal of Public Administration and Governance

ISSN 2161-7104

2016, Vol. 6, No. 3

The study employed case study research design which employs qualitative technics to collect and analyse the data. Purposive and accidental sampling was used to select the participants of this study. The community members were selected by the use of accidental sampling in five streets in Bigwa and Lukuyu wards while purposive sampling was used to select WEO, water projects representatives and street chairpersons. The reason behind the decided approach is to enable the researchers to obtain data from relevant sources and respondents and avoid biased selection of the sample to be included in the study. The numbers of respondents recruited for this study were 25, in which 20 community members, the Ward Executive Officers (WEO) of Bigwa and Lukuyu wards, one representative from water project and two street chairpersons. Semi structured in depth interview was used to collect data to allow probing for more information. This method helped to maintain flexibility and get more, complete and detailed information about the topic under investigation. In addition, it helps to capture broad information and feeling of the respondents.

Qualitative method of data analysis in which content analysis was used to analyze the data collected from the respondents. Verbal data was transcribed into text and analyzed based on its content. Firstly, the researcher reviewed all data collected several times to get understanding of content. The impression of collected data was noted to support data interpretation. Secondly the researcher organized and grouped the data according to the question asked and the interpretation of identified themes was made and the meaning was attached. In this step the researcher merged all similar themes and the conclusion was drawn from the analysis.

\section{Results}

The basic question addressed in this article is 'how community participates in initiation and implementation of water project in Bigwa and Lukuyu wards in MMC'. The results have shown that there is one project by the name of Maji Bigwa and Lukuyu (MABILU). However, there are other names used by the community members to refer to the same project. While the majority named it as 'TASAF project' TASAF support the project financially, others labelled it as 'Lukuyu project' which is the name of one of the ward where the project was implemented. The implementation of the project started in 2009 and it was officially opened in 2010. Since the inception of the project, the residents of the two wards are served with their own project i.e. MABILU water project, while other wards in MMC are served by MORUWASA (Morogoro Urban Water Supply Authority). This indicates a different arrangement to address water shortage compared to other wards in the council. In the interview with the citizens as well as street chairpersons and water project representatives, participants explained on how they were involved in the project and mentioned a number of activities they did before and during the implementation of the project. While the majority of the participants affirmed to participate in the decision making and implementation of the project, some participants claimed to participate by organizing and convincing other community members to participate in the project. Besides, some participants reflected on the possible explanations for not participating in decision making as well as in implementation of the project. Specifically the participants mentioned to participate in various activities as clarified below: 


\subsection{Participation in the initiation and decision making of the project}

The study finds that most of the interviewed respondents participated in the decision making of MABILU project. While the majority of the interviewed community members affirmed to participate in the discussion to start water project, there are few participants who said that they did not participate in the decision making. The respondents said that they participated in various meetings where several projects were initiated and further participated in the decision to prioritise water project. One of the interviewed citizens from Bigwa ward expressed that:

", I personally participated in the decision to choose water project in my ward. We were asked to mention our preferences and then to rate only one project to be implemented in our ward and we did that and water project was ranked number one"

Some participants went further and explained the reason that they decided to vote for water project. They said that water shortage in their wards was a chronic problem for many years and thus it was an opportunity for them to address it. One of the participants interviewed state that:

"You now our wards are not connected to MOROWASA and we did not have any reliable source of water. We spent most of our time to fetch water, but now we have a reliable source of water"

Most of the participants who were involved in the decisions to start the project informed that they get to know about the project via various announcements as well as public meeting. Some participants said that they were informed about the public meeting and the project in particular by the street chairpersons. This suggests that the citizens receive information from multiple sources which might be among the reasons for many people to participate in the projects. This was also affirmed by the WEO who said that:

"In all meeting, the first person to organize people is the street chairperson who is the link between the ward and the community at the street level. They are living with the people and thus they know better on how to organise them".

It was reported that the street chairpersons announce about the meeting few days before the meeting and they sometime move from one house to another to make sure that the citizens are informed. There are occasions where the citizens were asked by the street chairperson to inform other citizens about the meeting and the project in specific. This was confirmed by the participants who reported to inform their relatives and friends about the project.

On the other hand, there are participants who reported not to participate in the discussion to start projects. They informed that they were not aware of the meeting which discussed the project and made decision about it. Yet, this contradict with the perception of the project representative who claimed that the indigenous of Bigwa and Lukuyu wards are very reluctant to participate in the development stage of project especially when they are asked to give their opinion in the meeting. He said that:

"The indigenous of Bigwa have problem when it comes to giving out their views in the meeting particularly regarding the project. They expect other people and the government 
representatives to say everything for them. This is different from other people who know the need to participate in the decision of their own projects"

While the majority of the participants who participated in decision making of the project said that their opinions were considered, there are three participants who claimed that their opinions were not considered during the decision making. One of these participants claimed that she personally proposed a project to renovate road instead of water project. She said that water shortage was not an issue to her since she has water well at her home. She claimed that the road particularly the feeder road is not passable throughout the year so it would be much better to renovate it.

Besides, few participants felt that they were more involved in the implementation stage of the project than in the decision making of the project. They said that there was no much emphasis to involve citizens in making choice of the project as compared to the efforts to organize and engage citizens during the implementation stage. One of the participants in Lukuyu ward had the following to say during the interview:

"We are normally involved in doing various activities like digging and burying trench, but in most cases we were not fully involved in the decision making or in making choice of what we want"

There are basically two issues raised by the participants which might be an area for reflection and might be of importance to be considered when engaging the community. First, the fact that some participants felt their opinions was not considered during the decision making and second, the feeling of some participant that they were more involved in implementation than in decision making. The likely danger that might arise is lack of commitment during and after the implementation of the project which may affect the project as a whole.

\subsection{Money and manpower contribution}

The study has shown that most of the interviewed respondents participated in digging and burying trench, carrying building materials such as water pipes and cement and cleaning the project area. In addition, some participants reported to volunteer in planting trees around water sources and in water kiosk in order to preserve the environment. One of the interviewed water committee member stated that:

"The citizens participated in the project by digging canals, carrying building materials and other activities such as cleaning the project areas and planning the trees to preserve the environment around water sources"

Manpower contribution appears to be done by many participants compared to the number of participants who were involved in the decision making of the project. This, according to WEO was mandatory for each citizen of Bigwa and Lukuyu wards to participate since it was the agreement made by the citizens during the meeting. The agreement was that every citizen must participate by contributing either manpower or money or both. One of the interviewed WEO stated that: 
"It was the agreement made by the citizens themselves that they will contribute money or participate in performing different activities during the implementation of the project. The good thing is that most of them have tried to do that"

Some participants went further and reflected on the motive behind their commitment and contribution in implementing the project. The majority of the participants said that their motive was to see the project is successfully implemented so that they can get water from a reliable source. They further explained the way they struggled to solve the problem of water for many years, but they did not manage to find a reliable solution and thus they believed that water project would be a solution to their problem.

Apart from manpower contribution, it was reported by WEO and other interviewed citizens that some citizens contribute money to facilitate implementation of the project. Some participants contributed both money and manpower, while others contributed either money or manpower. After manpower contribution, money contribution was the highest activity which many people participated. Money contribution was mentioned by WEO and street chairperson as the agreement made by the citizens themselves that they should contribute their manpower in implementing the projects and those who did not have time to provide manpower should contribute money. During the interview with the WEO, he said that:

"As a ward executive officer, I had a role to make sure that the project is successful. One of the things I performed was to collect money from the citizens in the ward and those who did not have money were supposed to contribute their manpower".

He further clarified that

"The decision to contribute money and manpower was made by the citizens themselves in the meeting, so my role as a leader was to supervise and make sure that the decision of the meeting is implemented".

This was confirmed by some of the interviewed participants who said that they contributed money in supporting the implementation of the project since they did not have time to provide manpower. This shows a wide scope of participation given to citizens. The people who have failed to provide manpower were allowed to contribute money as a way to show their commitment to the project as well as compensation to what others have done in terms of manpower contribution.

\subsection{Participate by organizing and encouraging other people to participate}

Four participants who were initially the members of water committee and the street chairpersons performed different activities compared to other citizens. These are basically the leadership roles. They claimed that their task during the decision making and implementation of the project was to inform, organize and encourage citizens to participate in the project. They also performed the roles of managing, inspecting and supervising the construction of water kiosk and the projects as a whole, and surveying the project area before the actual construction. 


\section{Discussion and Conclusion}

The main objective of this article was to examine community participation in water projects in Bigwa and Lukuyu wards in MMC. The results shows that that the citizens of Bigwa and Lukuyu wards were involved in various activities including the decision making about the project, manpower and money contribution and organizing and convincing other people to participate. Particularly, the people of Bigwa and Lukuyu wards participated in digging and burying trench, in carrying building materials such as cement and water pipe and in cleaning project area. Similarly, some participants affirmed to participate by mobilizing the citizens to participate, managing and supervising the projects, supervising the construction of water kiosk, and surveying the project area.

Generally, the people of Bigwa and Lukuyu wards to large extent were involved in deciding and implementing water project in their wards. This was affirmed by many participants who indicated to be familiar with the projects as well as attending several meetings to discuss the project. However, the results shows that many of the interviewed respondents participate more in the late stages of the project implementation compared to the number of people who participated in the early stages of decision making about the project. The citizens indicated to be more committed to provide manpower and money to facilitate the implementation of the project than giving their views during in the decision making. This reflects the view of a project representative who said that the people in Bigwa and Lukuyu ward were reluctant to provide their views when making decision of the project.

It should be noted that the citizens of Bigwa and Lukuyu ward were given an opportunity to participate in the decision making of the project and they were informed about the meeting which discussed the project. The majority of the interviewed participants attended and participated in the decisions to initiate the project. This reflects interactive or partnership type of participation. Interactive participation implies a degree of citizen power where the citizens participate direct in the decision making and in planning about the project. The project was initially initiated from the bottom-at the community level and the citizens had power to affect the decisions. In fact this increases the credibility in terms of the involvement of the community in making the decision of the issues which affect them and their life.

Despite the fact that the project was initiated by the community members in the meeting, still participation of the citizens was low during the decision making of the project as compared to their participation in the implementation. This can be linked to another type of participation, which participation for material incentives. Participation for material incentives or induced participation is characterised with top-down participation, participation in implementation and sharing of benefits. The citizens, in this kind of participation, seem to have some power particularly during the implementation although their choice might be manipulated. This might be reflected by the view of few participants who felt that they were more involved in the implementation stage of the project as compared to their participation in the initial stage of the project. 
It is thus concluded that participation in Bigwa and Lukuyu wards reflect primarily interactive or partnership participation and marginally participation for material incentives which is sometimes called induced participation. The fact that the citizens were given full mandate to participate in the decision making of the project as well as in the implementation stage reflects interactive or partnership participation where the community members have power on the decision about the project. That the community members were given chance to initiate their need/demand and empowered to make decision and participate in implementing the projects. This entails granting power and empowering people to make decision that affect their own life that in turn motivates them to participate. This was typically reflected in Bigwa and Lukuyu during the initiation and implementation of water project where the beneficiaries were consulted during the project design to take into account their felt needs and aspirations. This resulted into successful implementation of water project in Bigwa and Lukuyu ward whereby the majority of the citizens are recently benefiting.

On the other hand participation for material incentive was marginally reflected in the wards. This was observed when some of the interviewed respondents reported not to attend the meeting that made the decision about the project despite the opportunity they had to participate. Most of the interviewed participants participated in providing the materials such as manpower and money to facilitate the implementation of the project. To some extent, this kind of participation is good for the community that it may increase a sense of ownership of the project. However, if the community members are not involved in the initiation, participation for material incentive may diminish motive of some people to participate in the projects since they might have a feeling that they have no power on making their own choice. Thus, both participation for material incentives and participation in decision making in which citizens have power on the decisions of the project was an important factor for successful implementation of water project.

\section{References}

Arnstein, S. R. (1969). A ladder of citizen participation. Journal of the American Institute of planners, 35(4), 216-224.

Cooke, B., \& Kothari, U. (2001). Participation: The new tyranny?. Zed Books.

Dulani, B. (2003). How participatory is participation in social funds? An analysis of three case studies from the Malawi Social Action Fund,(MASAF). Development, 23.

Fariborz, A and Ma`rof, B.R (2008), Tourism and community capacity building. A literature in Development. Intermediate Technology Publications Ltd, London

JOICFP (2000) A guidebook for the Development Sustainable, CBD/ CBS Programs, Tokyo.

Kamugisha, D. Swai, I. Kihoza, P and Ringo C. (2012) Digital communication media and citizens participation in political activities in Tanzania: Experience of Morogoro Municipal Council. Journal of Policy and Leadership, Mzumbe University, vol 1, issue number 2, Pg $121-136$ 
Kumar, S. (2002) Methods for Community Participation: A complete guide for Making: European Experiences in Global Perspectives, VNG International, The Hague

Masanyiwa, Z. S and Kinyashi, G.F (2008) Analysis of Community Participation in Projects, Institute of Development Studies, UK

Mwakasangula, E. and Faty P (2013) Community participation in Education as solution to school dropout: The experience of Bagamoyo and Kibaha Districts. Journal of Policy and Leadership, Mzumbe University, issue number 1, vol 2, Page 35-52.

NATIONAL BUREAU OF STATISTICS (NBS) and Office of Chief Government Statistician (OCGS) Zanzibar (2014) the 2012 Population and Housing Census: Basic Demographic and Socio- Economic Profile; Key Findings. Dar es Salaam, Tanzania: NBS and OCGS.

Nelson, N. and Wright, S. (eds.) (1995) Power and Participatory Development: Theory and Practice, UK

Njunwa K (2010) Community participation as a tool for development: local community's participation in primary education development in Morogoro, Tanzania. Master Thesis in Development Management, Unpublished report

Nyerere J.K (1968) Freedom and Socialism, Dar es Salaam. Oxford University Press

Oakley, P. (1991). Projects with people: The practice of participation in rural development. International Labour Organization.

Pateman, C (1970) Participation and democratic theory, UK: Cambridge University Press

Pretty, E.A (2003) Participation and accountability in development management, the journal of development studies, 40(2), pp 1-29.

Pretty, J. N. (1995). Participatory learning for sustainable agriculture. World development, 23(8), 1247-1263.

Rowe, G., \& Frewer, L. J. (2000). Public participation methods: A framework for evaluation. Science, technology \& human values, 25(1), 3-29.

Sibiya, N. (2010). An investigation of community participation trends in the rural development process in Nquthu, northern KwaZulu Nquthu, northern KwaZulu-Natal (Doctoral dissertation, University of Zululand).

Swai, I. Anasel, M.G and Masue, O.S (2013) Achievements and challenges of women special seats arrangements in Tanzania. Journal of Policy and Leadership, Mzumbe University. Issue number 1, vol 2, pg. 121-134

Teorell, J. (2006) Political participation and three theories of democracy: A research inventory and agenda, European Journal of Political Research ITDG, London

Theron, F (2005) Trends in micro level development, Pretoria: J.L. VanSchaik Publishers Making: European Experience in Global Perspectives, VNG International, The Hague. 
Tosun, C (2000) Limits to Community Participation in the Tourism Development process, Ankara, Turkey

Tosun, C. (1999). Towards a typology of community participation in the tourism development process. Anatolia, 10(2), 113-134.

URT (1998) The Constitution of the United Republic of Tanzania, Dar Es Salaam, Government Printer, Tanzania.

Verba, S. et al (1995) Voice and Equality: Civic Voluntarism in American Politics. Harvard University Press, London

Wilcox, D. (1994). The guide to effective participation. Brighton, UK: Partnership.

\section{Copyright Disclaimer}

Copyright for this article is retained by the author(s), with first publication rights granted to the journal.

This is an open-access article distributed under the terms and conditions of the Creative Commons Attribution license (http://creativecommons.org/licenses/by/3.0/). 